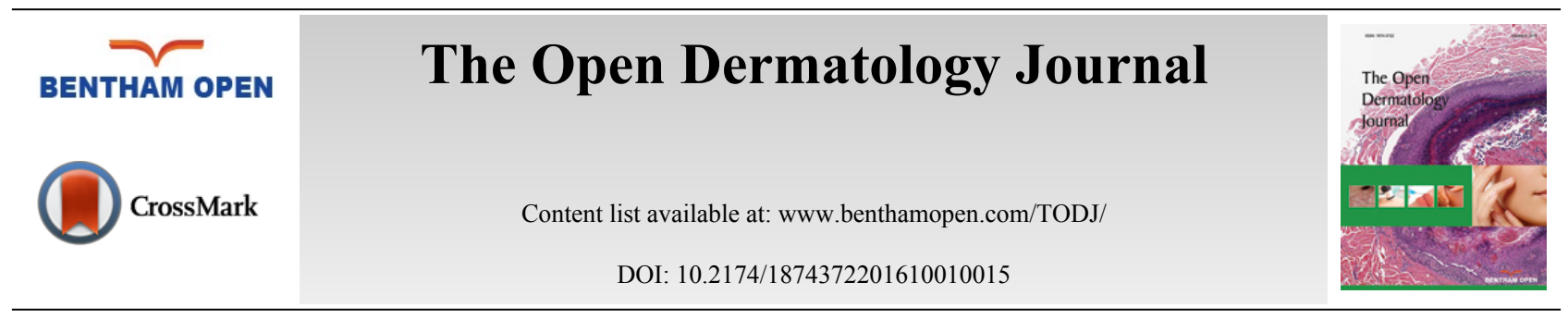

\title{
Epidemiology of Lyme Disease in Domestic and Wild Animals
}

\author{
Vittorio Sala ${ }^{*}$ and Eleonora De Faveri \\ Department of Veterinary Science and Public Health, University of Milan, Italy
}

\begin{abstract}
This review considers the main aspects of Lyme Borreliosis epidemiology in animals [domestic and wild] and ticks and in particular, the environmental interference on the interactions between the different hosts, including humans as terminal host as well as the current epidemiology of Lyme disease, especially based on the interactions between the biological systems involved in its spatial and temporal variations. The expression of pathogenic Borreliae occurs through interaction with the diverse stages of development of ticks and their blood meals from the different animal reservoirs and humans. The species of ticks and the prevalence of Borrelia species vary according to their provenance in the diverse continents. Reservoir animals have different functions depending on the respective species. Small rodents and some birds are responsible for retaining pathogens, while the large domestic and wild animals contribute to the increase in the number of ticks in the area and to the transmission of borreliosis among themselves through the cofeeding phenomenon. The dog on the other hand is a terminal host, as are humans, and both species may develop acute and chronic clinical forms, mainly of articular and neural nature. Climatic variations and changes in the duration of seasons may interfere with the biological cycles of animal species, arthropods and bacteria. These variations have led to a gradual change in the epidemiology of the infection and of the clinical evidence of the disease in different animal species as well as humans. Finally, the implications of Lyme disease in the field of social health have been considered. In fact, Lyme borreliosis is a zoonotic disease characterized by a major social impact, which is expressed by chronic disease with progressive disability and in costly treatment in the acute cases. Therefore, its presence in human populations is not merely a health issue.
\end{abstract}

Keywords: Animals, Borrelia burgdorferi s.l, lyme Disease, ticks.

Many pathogens which cause disease in humans or animals are preserved in specific biological niches, from which they emerge when transmission is possible. This "reservoir function" is closely related to the association between animal species and the pathogen, which must be able to remain vital and alive without interfering with the survival of the host. Another essential factor is the specificity of arthropod vectors for the diverse animal species, this is also essential for the development of any predictive model of disease risk. For a correct and complete interpretation of the epidemiology of any metazoonotic disease, the pathogen, the animal and the vector should therefore be considered in a systematic ecological vision. The ecological context, defined as the presence of plant and animal species and their reciprocal relationships, determines the balance and interactions that affect the quantity and circulation of Borrelia, its presence in the animal reservoir, its diffusion through tick populations and the possibility of human infection.

In the case of ticks, reservoir-associated groups exist in nature. Human exposure depends both on the degree of specificity of the vector to the host and the ways the ticks use to select one. Humans are always accidental hosts and the risk of exposure is based on these criteria [1].

Under these conditions, the estimated prevalence of infection based on the general characteristics of the tick population, may over or underestimate the risk of exposure.

However, pathogen transmission depends on the situation in which the host maintains the infection, as well as the specialization level of the vector. According to a recent epidemiological theory, a low degree of specialization can promote the circulation of a pathogen in many species, including humans. This theory also attributes a significant role

\footnotetext{
* Address correspondence to these authors at the Department of Veterinary Science and Public, Health University of Milan, Italy; E-mail: vittorio.sala@unimi.it
} 
to vector diversification in the modification of the epidemiology of associated diseases [2]. The diversification of vectors in an ecosystem increases the overall transmissibility of infection, regardless the number of species involved.

If vectors are already specialized in different animal species this connotation can be changed. To understand the environmental epidemiology of vectorborne diseases it is therefore necessary to know if the vectors are generalist or if the generalization is a phenomenon of adaptation due to the absence of the elective host.

Borrelia burgdorferi sensu lato is the agent of Lyme Disease and is transmitted by ticks of the genus Ixodes [3]. Interactions between $B$. burgdorferi and the vectors are specific to each geographic area and determine the incidence of infections in humans. For example, in the northeast of the United States, B. burgdorferi sensu stricto is mainly maintained by a cycle involving nymphs and larvae of Ixodes scapularis and the whitefooted mouse, Peromiscus leucopus [4].

Occasionally, nymphs or adults of I. scapularis can feed on a wide variety of vertebrates, including humans and transmit the infection. In other parts of the United States there are different species of the genus Ixodes hosting Lyme spirochetes, but their level of infection is low compared to that of the ticks of the areas with a high incidence of disease in humans $[5,6]$.

The modifications of the preferences of ticks for animal species may possibly explain the low prevalence of certain infections. For example, I. pacificus feeds on reptiles, which are not susceptible to spirochetal infection. I. neotomae is another potential vector and feeds on rodents, but rarely bites humans [5, 6]. In Europe and Asia, Lyme borreliosis is generally maintained by I. ricinus and I. persulcatus that are interspecific for different reservoir animals [7].

The tick blood meal lasts several days and during this time the arthropod moves together with the parasitized host, while also transmitting leading infections. The effective persistence of Borrelia infection in different vertebrate species is not fully known because the duration of bacteremia is subject to variations which depend on the state of the host and on the vitality of the involved bacterial strain. Small mammals such as rodents move in limited areas, while larger animals, such as deer, are able to move in territories with an area between 50 to 100 acres [8]. Birds can also deposit ticks far away from their original habitat being passive carriers of ticks infected with B. burgdorferi s.l., transporting them for long distances [9].

Therefore, migratory birds have a role in the movement of pathogens along their migratory routes, even for long distances. It has been also shown that some bird species can host a latent Borreliosis for several months. This infection can be reactivated and transmitted as a result of stress migration [10]. The transmission of B. burgdorferi s.l. is hardly subject to seasonal variations of tick activity if infected reservoirs remain available in any season [11].

In this study, the available information about the territorial epidemiology of Lyme Borreliosis, regarding Borrelia burgdorferi, ticks, reservoir animals, environmental interference and human behavior was then evaluated.

\section{BORRELIA}

B. burgdorferi has acquired a remarkable ability to survive in a wide variety of animals, such as arthropods and vertebrates mammals and birds. Unlike other pathogenic bacteria, most of its genome more than $8 \%, 150$ genes encodes for the production of lipoproteins $[12,13]$.

The ability of the bacterium to change its genomic structure to express different surface lipoproteins in the different stages of its life cycle has been demonstrated. This allows a complete host adaptation in mammals and in ticks and facilitates immune evasion $[14,15]$.

The host receptors involved in the interaction with Borrelia are few and this facilitates its survival in different organs. Besides the selective activation of genes, other events such as variable recombination contribute to the structural changes of the bacterium. The life cycle of $B$. burgdorferi is complex and deeply intertwined with that of its vertebrate host and arthropod vector. The bacterium enters the tick midgut during the blood meal on an infected animal. In this phase, an important protein, called OspA, upregulates its outer surface [12,16] and Borrelia establishes its localization through an interaction between OspA and a protein of the tick midgut called TROSPA [17].

This interaction allows the binding of spirochetes with the midgut, protecting them from the digestive and defensive processes [17]. This bond remains even during the molt of the tick, and between one blood meal and the next.

The replicative cycle of the bacterium strengthens during blood meals. When the bacterial load is higher, the Borreliae migrate from the midgut through the hemolymph to the salivary glands, which are the way out from the 
vertebrate host [17].

In this phase the spirochete downregulates OspA and the tick downregulates TROSPA [17]. This synchronized modification causes the detachment of the spirochete from the midgut and the start of the production of OspC, which is another surface lipoprotein [18].

The expression of OspC facilitates the exit of Borrelia from the gut of the tick and its localization in its salivary glands which is essential for the infection of vertebrate hosts [17]. Nymphs do not transmit the infection during the first day of feeding, while this capacity increases progressively from the third day onwards [19].

The kinetics of the transmission corresponds to the timing of Borrelia multiplication and to the expression of the different Osps. In the adult tick, transmission is possible from the first day for I. ricinus and I. persulcatus and the probability increases in relation to the number and the length of the blood meals [20]. Through OspC typing, distinct genotypes of $B$. burgdorferi sensu stricto were identified in ticks coming from US and Europe. Furthermore, genotypes of other members of the B. burgdorferi sensu lato complex [B. afzelii, B. garinii, B. lusitaniae, B. spielmanii, and B. valaisiana] have also been identified and genotyped. Significant $B$. burgdorferi s.s. genotypic diversity was observed between North American and European strains: only $6.6 \%$ of U.S. genotypes were found in Europe while $27 \%$ of the European genotypes were observed in the U.S. Adult Ixodes scapularis ticks from North America were infected with more than one genotype of $B$. burgdorferi s.s. and Ixodes ricinus ticks from Germany were infected with more than one genotype of $B$. burgdorferi s.1. [21].

Borrelia is a highly mobile organism and once having entered the skin layers, spreads through the dermis, causing the characteristic "bull's eye" lesion, which in humans is called erythema migrans. In the days and weeks after the first infection, Borreliae reaches other sites, such as the heart, joints, nervous tissue or distant skin sites [22, 23].

In Lyme disease, the infection of different organs corresponds to a wide variety of clinical expressions, such as flulike symptoms, secondary erythematous lesions, myocarditis, arthralgia and arthritis and a variety of neurological problems [24]. Chronic infection results in long term events, such as arthritis, dermatitis and neuroborreliosis [25].

Therefore Borrelia burgdorferi can colonize different structures of the host, including the skin, heart, bladder, nervous tissue and joints. In each of these points it can cause persistent infection, despite immune response [26]. The first important step in colonization is the interaction between the pathogen and the host tissue, mediated by different adhesins which are site specific $[27,28]$.

Genetic and biochemical studies have therefore identified the receptor sites of different hosts and the various proteins of Borrelia involved in adhesion. Borrelia enters the dermis during the tick blood meal and establishes an initial local infection which subsequently spreads to distal sites of multiplication. Finally, the infection becomes chronic and the bacterium hides in the joints and nervous tissue [28].

The clinical progression of Lyme disease indicates the existence of an expression of several timed adhesins that determine the sequence of events. It has been shown that the protein P66 encoded by chromosomes binds Borrelia to activated platelets. In addition, the link with the endothelium of blood vessels facilitates the spread of the spirochetes through the blood [29]. The expression of P66 starts during the tick blood meal, to prepare its transmission to a mammalian host, while it is not expressed in carrier fasting ticks. Instead, it is fully expressed in the mammalian host [30].

Borrelia burgdorferi is also capable of binding to fibronectin, which is a glycoprotein complex located in the extracellular matrix and plasma. The protein of Borrelia equipped with this capacity and best characterized is BBK32 which is expressed during the tick blood meal and in the mammalian host [31]. The spirochetes of the genus Borrelia also bind decorin, a proteoglycan associated with different human and murine tissues [32].

The link with decorin is essential to escape humoral immunity. In fact, the binding with host proteins masks Borrelia within some tissues. However, this process is also possible in the absence of decorin, and in this case the spirochete is however able to spread and to hide in other manners. So, Borrelia may also bind to glycosaminoglycans other than decorin with a protein called Bgp Borrelia GAG binding protein and possibly using other not yet discovered proteins. The genetic identification of these adhesins would be essential for understanding the pathogenesis of Lyme disease [29].

To date, the only adhesins identified on genetic basis are OspA and B which both mediate the bacterium adhesion to the tick midgut. Any functional loss of operon OspA / B would make this process impossible [33]. 
When TROSPA is blocked, the colonization alters, but does not stop. Taken together, these observations suggest that OspB can mediate adhesion to the tick midgut through other molecules. In this context of transmission the function of OspC must also be considered [17].

\section{ANIMAL EPIDEMIOLOGY}

Ticks are particularly interesting organisms because of the evolution of their host range and of the consequences in the epidemiological spread of disease. In case of infestation in great numbers they can even disrupt the reproductive dynamics of the host populations [34, 35].

Looking ahead, the greater biodiversity of the guests and the acquisition of skills by the vector of new species of ticks, may change the dynamics of disease transmission.

Correctly interpreting these bonds is therefore essential to predict population dynamics and the epidemiology of tickborne diseases [36].

Among the vectors, arthropod ticks are those that transmit the largest variety of pathogens, both in human and veterinary medicine. The infection of ticks originates from animals which act as reservoirs. In these animals, Borrelia is able to survive for very long periods of time in practice the reservoir's entire life without causing obvious signs of pain, often with only nonspecific symptoms associated with the periodic bacteremia. Even on the basis of what has been observed over the years, it is possible that not all reservoir animals, be they domestic or wild, have yet been identified. Furthermore, there are species that are only occasionally reservoirs of Borrelia [37].

The reservoirs in North America include small rodents such as white-footed mice Peromyscus leucopus chipmunks Tamia striatus and raccoons Procio lotor. On the other hand ungulates such as whitetailed deer Odocoileus virginianus, despite not having spirochetemia outside the clinical phases, represent a major food source for ticks therefore the increase of their numbers in any area is important. In Europe the role of the Roe deer Capreolus capreolus is relevant because its presence is associated with an increase in the number of ticks of the genus Ixodes [38].

In Europe, the function of wild animal reservoir is performed by voles Clethrionomys glareolus, Apodemus flavicollis and Apodemus sylvaticus and insectivores like hedgehogs Erinaceus europaeus. In absence of these animals, the pathogen can be maintained by the hare Lepus europaeus [39].

The reservoirs that can be infected by Borrelia and pass it to uninfected ticks include many species of small and mediumsized rodents mice, rats, squirrels, hares and rabbits, and several species of birds, mostly passerines, reptiles and insectivores [40].

In contrast, many wild and domestic large vertebrates e.g., deer and sheep are considered noncompetent reservoirs, i.e. the ticks that feed on them do not acquire Borrelia, but can infect one another through cofeeding [41].

Host specificity is the result of the resistance or sensitivity of the Borrelia genospecies to the serum complement of various host species, which leads to the death or survival of the pathogen, respectively [42]. Noncompetent reservoirs, like deer, can also serve as maintaining host for all the developmental stages of ticks [43].

Presence and number of these hosts are frequently associated with the density of tick populations, but their effect on the dynamics of the infection is complex. The presence of non- competent reservoirs may decrease potential infection transmission, reducing the prevalence of Borrelia in the vector dilution effect and as a result the risk of illness for humans [44].

On the other hand, they determine an increase of the number of ticks in the area where they live and if competent hosts are also present in large numbers the risk for humans may even increase [45].

For Borrelia garinii and Borrelia lusitaniae the reservoir function can be carried out by birds, such as pheasants (Phasianus colchicus) and especially the passerines (Turdus merula) [46]. More recently, migrating seabirds such as razorbills (Uria algae and Alca torda), parasitized by Ixodes uriae have also been reported. These birds may be responsible for the spread of the different species of Borrelia from one continent to another [9].

Occasional hosts may become ill, but the infection is blocked by their immune reaction and therefore they do not enter the transmission cycle, except for the period of bacteremia during the acute phase of the clinical form. Man and dog both have these characteristics as well as some ungulates and wild mammals [47].

Ticks therefore acquire Borrelia during the blood meal on an infected reservoir, meal which can last several days. 
The high prevalence of infected ticks in some ecosystems can be explained by the phenomenon of "co-feeding" that is the passage of Borrelia from one infected tick to another feeding on the same animal, even if the latter is not a reservoir. In this case, the transmission from one tick to another occurs in the superficial layers of the epidermis of the host and the phenomenon is frequent when the ticks are attached in groups, in large numbers and in the same area of the skin [48].

The ixodid ticks, unlike other hematophagous arthropod vectors feed for 4 to 8 days on vertebrate hosts to reach satiety [49]. This time is sufficient for spirochetes to migrate to the vertebrate host. This obviously involves adaptation phenomena that are not always easy for the pathogen [50].

During the feeding process, the tick penetrates the dermis, getting its blood meal from the hematoma that forms at the site of entry. However, this process activates the hemostatic and innate immune response of the host and therefore the selective migration of neutrophils and macrophages [51].

Therefore, it would seem inconvenient for Borrelia to choose to interface its replicative cycles with those of ticks. Instead, what has been gradually understood about the transcriptome of the tick [52] has clarified that the spirochete draws a distinct advantage from this mechanism of penetration into the host.

During a blood meal several salivary proteins that are potent suppressors of defense mechanisms are produced. They act in various ways hampering the activities of neutrophils, macrophages, B and T lymphocytes and complement cascades. These mechanisms are undoubtedly beneficial to Borrelia during emission from the tick and entry in the vertebrate host [53].

\section{LYME DISEASE IN DOGS}

Canine infection by B. burgdorferi sensu stricto has been discussed for three decades, after these spirochetes were identified as the cause of Lyme arthritis in humans. Dogs are susceptible to B. burgdorferi under experimental conditions because Borrelia migrates to the joint capsule and causes clinically mild arthritis [54].

The correlation of naturally acquired B. burgdorferi infection with clinical signs in dogs is very difficult and a definite diagnosis of canine borreliosis in naturally infected dogs is very difficult to obtain through the demonstration of B. burgdorferi within the host. Consequently, the definition "canine borreliosis" is used for seropositive dogs with or without non-specific clinical signs, such as pyrexia, lameness, myalgia and lethargy. The term 'Lyme nephritis' has instead been used for a syndrome of proteinlosing, immune complex nephropathy that occurs more frequently in certain breeds of dogs. Less than $2 \%$ of seropositive dogs develop this disease, with lameness reported in $9-28 \%$ of such cases [55].

The unconfirmed assumption that canine borreliosis is comparable to the human disease is certainly not true, because less than 5\% of dogs with suspected Lyme disease actually have the disease due to the B. burgdorferi [56].

B. burgdorferi s.l. has been identified in canine blood and urine samples by PCR [57] and other studies have suggested that $B$. burgdorferi invades the soft tissues of dogs after transmission by ticks, but rarely appears in the blood stream or in the urine of infected dogs [56].

Therefore, the risk of infection depends on the number of ticks infesting a dog and by how many of these are infected. The risk may be assessed by a sampling of ticks from dogs and from the environment, but the results are variable [58].

Despite the low percentage of clinical disease in dogs, some vaccines have been used in North America and Europe. Two types of vaccines are based on whole cell lysate and on recombinant OspA. This antibody response binds OspA expressed by B. burgdorferi in the tick's gut during blood meal, preventing the migration of the pathogen to the salivary gland of the tick and subsequently the transmission to the dog [59].

\section{ENVIRONMENTAL AND CLIMATE FACTORS}

The ability of ticks in transmitting Borrelia to various hosts is conditioned by several intrinsic factors, such as questing behavior, the duration of diapause, host specificity, coupling strategy and the number of the ticks in the area [60]. Extrinsic biotic and abiotic factors are the climatic conditions, the type of vegetation and its seasonality, the behavior of the reservoir, their abundance and susceptibility to the tick species present in the area [61].

Ticks infected with Borrelia show greater host research activity. Above all, the tick-host interaction is important for 
the dynamics of Borrelia infection, since during the blood meal the tick secretes salivary vasoactive mediators and immunomodulators that facilitate the transmission in both directions [62]. Furthermore, the efficiency of the passage can vary in relation to the genospecies of Borrelia and duration of host bacteremia [63].

Tick nymphs are the principal agent of Borrelia transmission to humans and attack more actively from spring to autumn in microenvironments with over $85 \%$ relative humidity, like deciduous or mixed forests with high ecotone rates [64], but are also active in in suburban and urban environments and on the edges of roads [65].

In an area infested by ticks, the risk of infection for a human being is high with an infected tick per person for every hour of exposure, or with 0.25 infected ticks for 100 meters walking distance [63]. The transmission of Borrelia does not usually occur within the first 24 hours of the blood meal and thus the immediate removal of ticks is a highly recommended preventive measure. Some factors influence the vector role of ticks and the abundance of animal reservoirs in the area. Among them, the use of the soil and the changes produced by human activities or natural causes can change the habitats of ticks and the composition of animal populations [66].

Even more important are global changes, such as climate change, which have direct effects on the survival and development of ticks. But these changes also have indirect effects on tick abundance, which depends on the composition of plant and animal species. Finally, the length of the seasons determines the periods of tick activity [67].

Length of the seasons, daily temperature and humidity are important for the survival, development and activity of ticks. Ticks are activated when the temperature exceeds $4-5^{\circ} \mathrm{C}$. Below this level they are in a state of biological inactivity $[68,34]$ while higher temperatures [between 8 and $10-10-11^{\circ} \mathrm{C}$ ] are required for the development of eggs and for the metamorphosis [69].

Ticks increase their activity and metamorphosis when spring starts earlier and autumn is prolonged. The speeding up of life cycles increases the frequency of tick bites and blood meals [68]. Larvae and nymphs of I. ricinus that feed at the beginning of the season evolve to the next stage of life in 1-3 months, while those that feed in the second part of the season enter into the diapause, hibernate and evolve the following year [70].

Seasonal tick activity peaks [in spring and autumn] have been reported. The occurrence of the different stages of tick species may vary within years and regions [71 - 73]. In habitats where dry periods are common, the periods of activity will be shortened to a few weeks, while they can last for several months in woodlands with a higher degree of humidity [74].

Adult ticks survive a couple of months at $-5^{\circ} \mathrm{C}$ and resist to air temperatures up to $-10^{\circ} \mathrm{C}$ for one month if they are not in direct contact with ice [75]. They overwinter in the ground covered by vegetation. A thick layer of snow can be favorable for survival because it increases soil temperature by several degrees. The effect of the snow cover depends on the thickness of the snow, its permanence, on the physical characteristics of the soil and the air temperature [76].

During host-seeking periods (questing) the ticks climb onto vegetation and are particularly vulnerable if the humidity is low. The larvae are more sensitive than adults and nymphs to temperature and lack of moisture [77]. The ticks' need to maintain a stable osmotic balance is an important factor in determining the position and duration of the hostseeking activities [78]. In the nonparasitic phase, I. ricinus requires a minimum humidity of $80-85 \%$ at the base of the vegetation [79]. Therefore, the characteristics of the vegetation are important for the maintenance of the tick population of an area.

The density of ticks is the combined effect of climatic and environmental conditions that have occurred in several years. Longterm studies have shown that the density, as well as the risk of disease in the course of a given year, are related to the number of days per season with favorable temperatures for tick activity, but also to their development and survival during the two previous years. So weather conditions have direct effects on the ticks' survival and their life cycle, but also indirect implications on the prevalence and risk of disease [80].

The risk of Lyme borreliosis in humans in a given area depends on the number of infectious ticks and on the factors that favor human exposure to them. For example, weather conditions affect human behavior: if the weather is not favorable, human recreational activity normally does not take place outdoors [81]. Forested areas and marginal grasslands like parks are favorite locations of ticks. Long term climate change in the may alter the characteristics of the vegetation, while the expansion of urban areas can reduce the risk of tickborne diseases [82].

Weather conditions, such as temperature and precipitations, affect the microclimate of the tick habitat, which in turn determines their survival and activity. However, climate modification may cause changes in the composition of the 
vegetation and in its life, but may also affect the spatial distribution and prevalence of tick and host animal populations. Even the snow conditions can affect winter survival of both species. A massive snowfall is favorable to hibernation of small mammals because ground temperatures are higher, while deep, ice-covered snow can be lethal for ruminants such as deer, which feed on twigs and undergrowth vegetation [83].

Since 1950, the minimum temperatures at night have increased proportionately more than daytime temperatures in the northern hemisphere [84]. Winter temperatures have increased more than those of the other seasons, especially at high latitudes [85]. In Europe, spring starts two weeks earlier than it did before 1980 and the duration of the seasonal vegetation has increased [84]. All these factors are important for the survival of ticks and thus for the risk of LB.

The effects of climate change are more easily recognized in areas located close to the limits of geographical distribution latitude and altitude of a given animal species. Changes in latitude in the distribution of ticks between the early 1980s and the mid-1990s have been studied in northern Sweden [86, 38]. Analysis showed that the spatial and temporal distribution was related to daily and seasonal climate change [87]. The appearance of new tick populations at higher latitudes was the result of less rigid winter temperatures and the increase in the number of days with temperatures suitable i.e. $>10^{\circ} \mathrm{C}$ for the reproduction of ticks [87].

The changes in the incidence of a disease in a country during a predetermined period of time are related to daily and seasonal climate modification, parameterized as "days of accumulated temperature" [80, 88].

Global temperatures will continue to rise at a faster rate and will be associated with changes in precipitation and wind, causing more instability in regional climates. A report by the Intergovernmental Panel of the United Nations on Climate Change has provided for Europe a generally milder climate and an increase of precipitations over the next 50-100 years. The impact of climate variability on the incidence of a disease is much more complex than the effects of climate on the distribution and population density of vectors. In fact, the long term studies of the effects of climate change on the ability of ticks to transmit diseases have presented several scientific problems; the variability between sites and over time, the differences in the awareness, the method of diagnosis and monitoring are just a few of these [84].

The possible impact of future climate change on LB risk in Europe can be hypothesized investigating the effect of climate on the spatial and temporal behavior of I. ricinus through biological models that take into account the seasonal trend and the distribution of ticks. Until now statistical "patternmatching" models have been used, but the information obtained should be used with great caution [73].

\section{CONCLUSION}

In many countries, information on the risk of Lyme disease is lacking and especially children, who are most at risk, are not properly informed on the use of the self-protection methods. Although the economic and technological level of society is increasingly high, public health organizations are sometimes unable to identify the risk and to provide timely diagnosis of subclinical diseases, such as Lyme borreliosis.

From the public health point of view, what is known on tick activity has two main implications. Firstly, the ticks are active in a variety of climatic conditions greater than those expected. Secondly, they are concentrated and multiply easily in recreational areas that attract large numbers of visitors. It would be necessary to determine whether the activities engaged by visitors influence the likelihood of contact with ticks [89].

Current levels of knowledge of the LD risk by the population are very limited, and this does not allow a correct perception. Consequently, also the risk related to tick bites is underestimated, both by people and sometimes by doctors, and this does not allow an early diagnosis of LD and a timely initiation of therapy in many cases [90].

Most people are not aware that ticks can transmit pathogens and therefore do not take any steps to prevent bites. Public health organizations should address this lack of knowledge. It would also be important to determine whether there are factors associated with changes in awareness and what the causes that alter the perception of risk are [91].

What therefore we need is an interdisciplinary and interspecific vision of the epidemiology of borreliosis. Assessing the risk in humans considering ethology and ecology of all the species that interact in its genesis and manifestation is the only way to decrease the number of clinical forms in humans. The dermatologic manifestation, which is the first sign of the disease in humans, may instead be used, regarding the location in which the patient lives or works, as an indicator of the potential environmental risk. 
Sharing of objectives and methods between dermatologist and veterinarian infectivologist and parasitologist is probably the only solution for an increasing Public Health problem.

\section{CONFLICTS OF INTEREST}

The authors confirm that this article content has no conflict of interest.

\section{ACKNOWLEDGEMENTS}

Declared none.

\section{REFERENCES}

[1] Balashov YS. Significance of Ixodid tick (Parasitiformes, Ixodidae) population structure for maintenance of natural foci of infection. Biol Bull 2010; 37: 677-83. [http://dx.doi.org/10.1134/S1062359010070022]

[2] Roche B, Rohani P, Dobson AP, Guégan JF. The impact of community organization on vectorborne pathogens. Am Nat 2013; $181(1)$ : 1-11. [http://dx.doi.org/10.1086/668591] [PMID: 23234841]

[3] Malawista SE. Lyme disease. Philadelphia, PA: Saunders, W.B 1992; pp. 1772-7.

[4] Nadelman RB, Wormser GP. Lyme borreliosis. Lancet 1998; 352(9127): 557-65. [http://dx.doi.org/10.1016/S0140-6736(98)01146-5] [PMID: 9716075]

[5] Brown RN, Lane RS. Lyme disease in California: a novel enzootic transmission cycle of Borrelia burgdorferi. Science 1992; 256(5062): $1439-42$.

[http://dx.doi.org/10.1126/science.1604318] [PMID: 1604318]

[6] Steere AC. Lyme disease. N Engl J Med 2001; 345(2): 115-25. [http://dx.doi.org/10.1056/NEJM200107123450207] [PMID: 11450660]

[7] Stanek G, Satz N, Strle F, Wilske B. Epidemiology of Lyme borreliosis. Berlin, Germany: Springer-Verlag 1993 ; pp. 358-70. [http://dx.doi.org/10.1007/978-3-642-77614-4_29]

[8] Lindgren E, Jaenson TG. Lyme borreliosis in Europe: influence of climate and climate change, epidemiology, ecology and adaptation measures. WHO Regional Office for Europe 2006.

[9] Olsén B, Jaenson TG, Bergström S. Prevalence of Borrelia burgdorferi sensu latoinfected ticks on migrating birds. Appl Environ Microbiol 1995; 61(8): 3082-7.

[PMID: 7487041]

[10] Gylfe A, Bergström S, Lundström J, Olsen B. Reactivation of Borrelia infection in birds. Nature 2000; 403(6771): 724-5. [http://dx.doi.org/10.1038/35001663] [PMID: 10693792]

[11] Randolph SE. The shifting landscape of tick-borne zoonoses: tick-borne encephalitis and Lyme borreliosis in Europe. Philos Trans R Soc Lond B Biol Sci 2001; 356(1411): 1045-56.

[http://dx.doi.org/10.1098/rstb.2001.0893] [PMID: 11516382]

[12] De Silva AM, Fikrig E. Growth and migration of Borrelia burgdorferi in Ixodes ticks during blood feeding. Am J Trop Med Hyg 1995; 53(4): 397-404.

[PMID: 7485694]

[13] Grimm D, Tilly K, Byram R, et al. Outer-surface protein C of the Lyme disease spirochete: a protein induced in ticks for infection of mammals. Proc Natl Acad Sci USA 2004; 101(9): 3142-7.

[http://dx.doi.org/10.1073/pnas.0306845101] [PMID: 14970347]

[14] Casjens S, Palmer N, van Vugt R, et al. A bacterial genome in flux: the twelve linear and nine circular extrachromosomal DNAs in an infectious isolate of the Lyme disease spirochete Borrelia burgdorferi. Mol Microbiol 2000; 35(3): 490-516. [http://dx.doi.org/10.1046/j.1365-2958.2000.01698.x] [PMID: 10672174]

[15] Rosa PA, Tilly K, Stewart PE. The burgeoning molecular genetics of the Lyme disease spirochaete. Nat Rev Microbiol 2005; 3(2): 129-43. [http://dx.doi.org/10.1038/nrmicro1086] [PMID: 15685224]

[16] Schwan TG, Piesman J, Golde WT, Dolan MC, Rosa PA. Induction of an outer surface protein on Borrelia burgdorferi during tick feeding. Proc Natl Acad Sci USA 1995; 92(7): 2909-13. [http://dx.doi.org/10.1073/pnas.92.7.2909] [PMID: 7708747]

[17] Pal U, Li X, Wang T, et al. TROSPA, an Ixodes scapularis receptor for Borrelia burgdorferi. Cell 2004; 119(4): 457-68. [http://dx.doi.org/10.1016/j.cell.2004.10.027] [PMID: 15537536]

[18] Stevenson B, Schwan TG, Rosa PA. Temperature-related differential expression of antigens in the Lyme disease spirochete, Borrelia burgdorferi. Infect Immun 1995; 63(11): 4535-9.

[PMID: 7591099]

[19] Piesman J, Mather TN, Sinsky RJ, Spielman A. Duration of tick attachment and Borrelia burgdorferi transmission. J Clin Microbiol 1987; 
25(3): 557-8.

[PMID: 3571459]

[20] Schwan TG, Piesman J. Vector interactions and molecular adaptations of lyme disease and relapsing fever spirochetes associated with transmission by ticks. Emerg Infect Dis 2002; 8(2): 115-21. [http://dx.doi.org/10.3201/eid0802.010198] [PMID: 11897061]

[21] Crowder CD, Matthews HE, Schutzer S, et al. Genotypic variation and mixtures of Lyme Borrelia in Ixodes ticks from North America and Europe. PLoS One 2010; 5(5): e10650.

[http://dx.doi.org/10.1371/journal.pone.0010650] [PMID: 20498837]

[22] Nadelman RB, Wormser GP. Erythema migrans and early Lyme disease. Am J Med 1995; 98(4A): 15S-23S [http://dx.doi.org/10.1016/S0002-9343(99)80040-0] [PMID: 7726187]

[23] Wormser GP. Clinical practice. Early Lyme disease. N Engl J Med 2006; 354(26): 2794-801. [http://dx.doi.org/10.1056/NEJMcp061181] [PMID: 16807416]

[24] van Dam AP, Kuiper H, Vos K, et al. Different genospecies of Borrelia burgdorferi are associated with distinct clinical manifestations of Lyme borreliosis. Clin Infect Dis 1993; 17(4): 708-17. [http://dx.doi.org/10.1093/clinids/17.4.708] [PMID: 7903558]

[25] Balmelli T, Piffaretti JC. Association between different clinical manifestations of Lyme disease and different species of Borrelia burgdorferi sensu lato. Res Microbiol 1995; 146(4): 329-40. [http://dx.doi.org/10.1016/0923-2508(96)81056-4] [PMID: 7569327]

[26] Liang FT, Jacobs MB, Bowers LC, Philipp MT. An immune evasion mechanism for spirochetal persistence in Lyme borreliosis. J Exp Med 2002; 195(4): 415-22 [http://dx.doi.org/10.1084/jem.20011870] [PMID: 11854355]

[27] Coburn J, Medrano M, Cugini C. Borrelia burgdorferi and its tropisms for adhesion molecules in the joint. Curr Opin Rheumatol 2002; 14(4): 394-8. [http://dx.doi.org/10.1097/00002281-200207000-00010] [PMID: 12118173]

[28] Coburn J, Fischer JR, Leong JM. Solving a sticky problem: new genetic approaches to host cell adhesion by the Lyme disease spirochete. Mol Microbiol 2005; 57(5): 1182-95. [http://dx.doi.org/10.1111/j.1365-2958.2005.04759.x] [PMID: 16101994]

[29] Coburn J, Chege W, Magoun L, Bodary SC, Leong JM. Characterization of a candidate Borrelia burgdorferi beta3-chain integrin ligand identified using a phage display library. Mol Microbiol 1999; 34(5): 926-40. [http://dx.doi.org/10.1046/j.1365-2958.1999.01654.x] [PMID: 10594819]

[30] Coburn J, Cugini C. Targeted mutation of the outer membrane protein P66 disrupts attachment of the Lyme disease agent, Borrelia burgdorferi, to integrin alphavbeta3. Proc Natl Acad Sci USA 2003; 100(12): 7301-6. [http://dx.doi.org/10.1073/pnas.1131117100] [PMID: 12748384]

[31] Li X, Liu X, Beck DS, Kantor FS, Fikrig E. Borrelia burgdorferi lacking BBK32, a fibronectin-binding protein, retains full pathogenicity. Infect Immun 2006; 74(6): 3305-13. [http://dx.doi.org/10.1128/IAI.02035-05] [PMID: 16714558]

[32] Guo BP, Brown EL, Dorward DW, Rosenberg LC, Höök M. Decorin binding adhesins from Borrelia burgdorferi. Mol Microbiol 1998; 30(4): 711-23. [http://dx.doi.org/10.1046/j.1365-2958.1998.01103.x] [PMID: 10094620]

[33] Yang XF, Pal U, Alani SM, Fikrig E, Norgard MV. Essential role for OspA/B in the life cycle of the Lyme disease spirochete. J Exp Med 2004; 199(5): 641-8. [http://dx.doi.org/10.1084/jem.20031960] [PMID: 14981112]

[34] Duffy DC, Campbell SR. Ambient air temperature as a predictor of activity of adult Ixodes scapularis (Acari: Ixodidae). J Med Entomol 1994; 31(1): 178-80. [http://dx.doi.org/10.1093/jmedent/31.1.178] [PMID: 8158624]

[35] Boulinier T, Danchin E. Population trends in Kittiwake Rissa tridactyla colonies in relation to tick infestation Ibis 1996; 138(2): 326-34. [http://dx.doi.org/10.1111/j.1474-919X.1996.tb04345.x]

[36] Jones KE, Patel NG, Levy MA, et al. Global trends in emerging infectious diseases. Nature 2008; 451(7181): 990-3. [http://dx.doi.org/10.1038/nature06536] [PMID: 18288193]

[37] Parola P, Raoult D. Ticks and tickborne bacterial diseases in humans: an emerging infectious threat. Clin Infect Dis 2001; $32(6)$ : 897-928. [http://dx.doi.org/10.1086/319347] [PMID: 11247714]

[38] Tälleklint L, Jaenson TG. Increasing geographical distribution and density of Ixodes ricinus (Acari: Ixodidae) in central and northern Sweden. J Med Entomol 1998; 35(4): 521-6. [http://dx.doi.org/10.1093/jmedent/35.4.521] [PMID: 9701939]

[39] Hovmark A, Jaenson TG, Asbrink E, Forsman A, Jansson E. First isolations of Borrelia burgdorferi from rodents collected in northern Europe. APMIS 1988; 96(10): 917-20. [http://dx.doi.org/10.1111/j.1699-0463.1988.tb00962.x] [PMID: 3190915] 
[40] Brisson D, Dykhuizen DE, Ostfeld RS. Conspicuous impacts of inconspicuous hosts on the Lyme disease epidemic. Proc Biol Sci 2008; 275(1631): 227-35. [PMID: 18029304]

[41] Ogden NH, Tsao JI. Biodiversity and Lyme disease: dilution or amplification? Epidemics 2009; 1(3): 196-206. [http://dx.doi.org/10.1016/j.epidem.2009.06.002] [PMID: 21352766]

[42] Kurtenbach K, De Michelis S, Etti S, et al. Host association of Borrelia burgdorferi sensu lato the key role of host complement. Trends Microbiol 2002; 10(2): 74-9. [http://dx.doi.org/10.1016/S0966-842X(01)02298-3] [PMID: 11827808]

[43] Tsao JI. Reviewing molecular adaptations of Lyme borreliosis spirochetes in the context of reproductive fitness in natural transmission cycles. Vet Res 2009; 40(2): 36. [http://dx.doi.org/10.1051/vetres/2009019] [PMID: 19368764]

[44] Perkins SE, Cattadori IM, Tagliapietra V, Rizzoli AP, Hudson PJ. Localized deer absence leads to tick amplification. Ecology 2006; 87(8): 1981-6. [http://dx.doi.org/10.1890/0012-9658(2006)87[1981:LDALTT]2.0.CO;2] [PMID: 16937637]

[45] Keesing F, Belden LK, Daszak P, et al. Impacts of biodiversity on the emergence and transmission of infectious diseases. Nature 2010; 468(7324): 647-52. [http://dx.doi.org/10.1038/nature09575] [PMID: 21124449]

[46] Michalik J, Wodecka B, Skoracki M, et al. Prevalence of avian-associated Borrelia burgdorferi s.l. genospecies in Ixodes ricinus ticks collected from blackbirds (Turdus merula) and song trushes (T. philomenos). Int J Med Microbiol 2008; S1: 129-38. [http://dx.doi.org/10.1016/j.ijmm.2008.03.004]

[47] Robertson JN, Gray JS, Stewart P. Tick bite and Lyme borreliosis risk at a recreational site in England. Eur J Epidemiol 2000 ; $16(7)$ : 647-52. [http://dx.doi.org/10.1023/A:1007615109273] [PMID: 11078122]

[48] Randolph SE, Gern L, Nuttall PA. Co-feeding ticks: Epidemiological significance for tick-borne pathogen transmission. Parasitol Today (Regul Ed) 1996; 12(12): 472-9. [http://dx.doi.org/10.1016/S0169-4758(96)10072-7] [PMID: 15275266]

[49] Lahdenne P, Porcella SF, Hagman KE, et al. Molecular characterization of a 6.6-kilodalton Borrelia burgdorferi outer membrane associated lipoprotein (lp6.6) which appears to be downregulated during mammalian infection. Infect Immun 1997; 65(2): 412-21. [PMID: 9009290]

[50] Pal U, de Silva AM, Montgomery RR, et al. Attachment of Borrelia burgdorferi within Ixodes scapularis mediated by outer surface protein A. J Clin Invest 2000; 106(4): 561-9. [http://dx.doi.org/10.1172/JCI9427] [PMID: 10953031]

[51] Pal U, Montgomery RR, Lusitani D, et al. Inhibition of Borrelia burgdorferi-tick interactions in vivo by outer surface protein A antibody. J Immunol 2001; 166(12): 7398-403. [http://dx.doi.org/10.4049/jimmunol.166.12.7398] [PMID: 11390491]

[52] Munderloh UG, Kurtti TJ. Cellular and molecular interrelationships between ticks and prokaryotic tick-borne pathogens. Annu Rev Entomol 1995; 40: 221-43. [http://dx.doi.org/10.1146/annurev.en.40.010195.001253] [PMID: 7810987]

[53] Shih CM, Chao LL, Yu CP. Chemotactic migration of the Lyme disease spirochete (Borrelia burgdorferi) to salivary gland extracts of vector ticks. Am J Trop Med Hyg 2002; 66(5): 616-21. [PMID: 12201601]

[54] Appel MJ, Allan S, Jacobson RH, et al. Experimental Lyme disease in dogs produces arthritis and persistent infection. J Infect Dis 1993; 167(3): 651-64 [http://dx.doi.org/10.1093/infdis/167.3.651] [PMID: 8440936]

[55] Littman MP. Lyme nephritis. J Vet Emerg Crit Care (San Antonio) 2013; 23(2): 163-73. [http://dx.doi.org/10.1111/vec.12026] [PMID: 23461642]

[56] Littman MP, Goldstein RE, Labato MA, Lappin MR, Moore GE. ACVIM small animal consensus statement on Lyme disease in dogs: diagnosis, treatment, and prevention. J Vet Intern Med 2006; 20(2): 422-34. [http://dx.doi.org/10.1111/j.1939-1676.2006.tb02880.x] [PMID: 16594606]

[57] Bauerfeind R, Kreis U, Weiss R, Wieler LH, Baljer G. Detection of Borrelia burgdorferi in urine specimens from dogs by a nested polymerase chain reaction. Zentralbl Bakteriol 1998; 287(4): 347-61. [http://dx.doi.org/10.1016/S0934-8840(98)80170-9] [PMID: 9638865]

[58] Leschnik MW, Kirtz G, Khanakah G, et al. Humoral immune response in dogs naturally infected with Borrelia burgdorferi sensu lato and in dogs after immunization with a Borrelia vaccine. Clin Vaccine Immunol 2010; 17(5): 828-35. [http://dx.doi.org/10.1128/CVI.00427-09] [PMID: 20219882]

[59] Krupka I, Straubinger RK. Lyme borreliosis in dogs and cats: background, diagnosis, treatment and prevention of infections with Borrelia burgdorferi sensu stricto. Vet Clin North Am Small Anim Pract 2010; 40(6): 1103-19. [http://dx.doi.org/10.1016/j.cvsm.2010.07.011] [PMID: 20933139] 
[60] Kempf F, De Meeûs T, Arnathau C, Degeilh B, McCoy KD. Assortative pairing in Ixodes ricinus (Acari: Ixodidae), the European vector of Lyme borreliosis. J Med Entomol 2009; 46(3): 471-4. [http://dx.doi.org/10.1603/033.046.0309] [PMID: 19496415]

[61] Brunner JL, LoGiudice K, Ostfeld RS. Estimating reservoir competence of Borrelia burgdorferi hosts: prevalence and infectivity, sensitivity, and specificity. J Med Entomol 2008; 45(1): 139-47. [http://dx.doi.org/10.1603/0022-2585(2008)45[139:ERCOBB]2.0.CO;2] [PMID: 18283955]

[62] Faulde MK, Robbins RG. Tick infestation risk and Borrelia burgdorferi s.l. infection induced increase in host finding efficacy of female Ixodes ricinus under natural conditions. Exp Appl Acarol 2008; 44(2): 137-45.

[http://dx.doi.org/10.1007/s10493-008-9131-4] [PMID: 18273686]

[63] Kurtenbach K, Hanincová K, Tsao JI, Margos G, Fish D, Ogden NH. Fundamental processes in the evolutionary ecology of Lyme borreliosis. Nat Rev Microbiol 2006; 4(9): 660-9. [http://dx.doi.org/10.1038/nrmicro1475] [PMID: 16894341]

[64] Estrada-Peña A, Venzal JM, Sánchez Acedo C. The tick Ixodes ricinus: distribution and climate preferences in the western Palaearctic. Med Vet Entomol 2006; 20(2): 189-97. [http://dx.doi.org/10.1111/j.1365-2915.2006.00622.x] [PMID: 16874918]

[65] Haemig PD, Waldenstrom J, Olsen B. Roadside ecology and epidemiology of tick borne diseases. Scand J Infect Dis 2008; 40(11-12): 853-8. [http://dx.doi.org/10.1080/00365540802270003] [PMID: 18618374]

[66] Meiners T, Hammer B, Göbel UB, Kahl O. Determining the tick scutal index allows assessment of tick feeding duration and estimation of infection risk with Borrelia burgdorferi sensu lato in a person bitten by an Ixodes ricinus nymph. Int J Med Microbiol 2006; 296(Suppl. 40): 103-7.

[http://dx.doi.org/10.1016/j.ijmm.2006.01.048] [PMID: 16524770]

[67] Ostfeld RS. Biodiversity loss and the rise of zoonotic pathogens. Clin Microbiol Infect 2009; 15(Suppl. 1): 40-3. [http://dx.doi.org/10.1111/j.1469-0691.2008.02691.x] [PMID: 19220353]

[68] Balashov YS. Bloodsucking ticks (Ixodoidea) - vectors of diseases of man and animals. Miscel Publ Entom Soc Am 1972; 8: 163-76

[69] Clark DD. Lower temperature limits for activity of several Ixodid ticks (Acari: Ixodidae): effects of body size and rate of temperature change. J Med Entomol 1995; 32(4): 449-52.

[http://dx.doi.org/10.1093/jmedent/32.4.449] [PMID: 7650705]

[70] Tälleklint L, Jaenson TG. Transmission of Borrelia burgdorferi s.l. from mammal reservoirs to the primary vector of Lyme borreliosis, Ixodes ricinus (Acari: Ixodidae), in Sweden. J Med Entomol 1994; 31(6): 880-6. [http://dx.doi.org/10.1093/jmedent/31.6.880] [PMID: 7815401]

[71] Tälleklint L, Jaenson TG. Infestation of mammals by Ixodes ricinus ticks (Acari: Ixodidae) in south central Sweden. Exp Appl Acarol 1997; 21(12): 755-71. [http://dx.doi.org/10.1023/A:1018473122070] [PMID: 9423270]

[72] Zakovska A. Monitoring the presence of Borreliae in Ixodes ricinus ticks in Brno Park Pisarky, Czech Republic. Biologia 2000; 55(6): 661-6.

[73] Randolph SE, Green RM, Hoodless AN, Peacey MF. An empirical quantitative framework for the seasonal population dynamics of the tick Ixodes ricinus. Int J Parasitol 2002; 32(8): 979-89. [http://dx.doi.org/10.1016/S0020-7519(02)00030-9] [PMID: 12076627]

[74] Gray JS. The fecundity of Ixodes ricinus (L.) (Acarina: Ixodidae) and the mortality of its development stages under field conditions. Bull Entomol Res 1981; 71: 533-42. [http://dx.doi.org/10.1017/S0007485300008543]

[75] Knülle W, Dautel H. Cold hardiness, supercooling ability and causes of low temperature mortality in the soft tick, Argas reflexus, and the hard tick, Ixodes ricinus (Acari: Ixodoidea) from Central Europe. J Insect Physiol 1997; 43(9): 843-54. [http://dx.doi.org/10.1016/S0022-1910(97)00025-5] [PMID: 12770496]

[76] Berry MO. Snow and climate. In: Gray DM, Male DH, Eds. Handbook of snow. Toronto: Pergamon Press 1981; pp. $32-59$.

[77] Daniel M. Influence of the microclimate on the vertical distribution of the tick Ixodes ricinus (L.) in central Europe. Acarologica 1993; XXXIV(2): 105-13.

[78] Randolph SE, Storey K. Impact of microclimate on immature tick rodent host interactions (Acari: Ixodidae): implications for parasite transmission. J Med Entomol 1999; 36(6): 741-8. [http://dx.doi.org/10.1093/jmedent/36.6.741] [PMID: 10593075]

[79] Kahl O, Knülle W. Water vapour uptake from subsaturated atmospheres by engorged immature ixodid ticks. Exp Appl Acarol 1988; 4(1): 73-83.

[http://dx.doi.org/10.1007/BF01213843] [PMID: 3378463]

[80] Lindgren E, Gustafson R. Tick-borne encephalitis in Sweden and climate change. Lancet 2001; 358(9275): 16-8. [http://dx.doi.org/10.1016/S0140-6736(00)05250-8] [PMID: 11454371]

[81] Jaenson TG. The epidemiology of lyme borreliosis. Parasitol Today (Regul Ed) 1991; 7(2): 39-45. [http://dx.doi.org/10.1016/0169-4758(91)90187-S] [PMID: 15463419] 
[82] Kaiser R. Tick-borne encephalitis in southern Germany. Lancet 1995; 345(8947): 463-9. [http://dx.doi.org/10.1016/S0140-6736(95)90452-2] [PMID: 7853989]

[83] Cederlund G, Liberg O. The roe deer Wildlife, ecology and hunting. Uppsala: Almqvist and Wiksell 1995.

[84] IPCC. Climate change 2001: The third assessment report of the Intergovernmental Panel on Climate Change. Cambridge: Cambridge University Press 2001 .

[85] Easterling DR, Horton B, Jones FD. Maximum and minimum temperature trends for the globe. Science 1997; $277: 363-7$. [http://dx.doi.org/10.1126/science.277.5324.364]

[86] Jaenson TG, Tälleklint L, Lundqvist L, Olsen B, Chirico J, Mejlon H. Geographical distribution, host associations, and vector roles of ticks (Acari: Ixodidae, Argasidae) in Sweden. J Med Entomol 1994; 31(2): 240-56. [http://dx.doi.org/10.1093/jmedent/31.2.240] [PMID: 8189415]

[87] Lindgren E, Tälleklint L, Polfeldt T. Impact of climatic change on the northern latitude limit and population density of the diseasetransmitting European tick Ixodes ricinus. Environ Health Perspect 2000; 108(2): 119-23. [http://dx.doi.org/10.1289/ehp.00108119] [PMID: 10656851]

[88] Lindgren E. Climate and tick-borne encephalitis. Conserv Ecol. Available at: http://www.consecol.org/Journal/vol2/iss1/art5/. 1998 [Accessed on: 13 Dec 2003];2(1): 1-14.

[89] O’Connell S, Granström M, Gray JS, Stanek G. Epidemiology of european lyme borreliosis. Zentralbl Bakteriol 1998; 287(3): 229-40. [http://dx.doi.org/10.1016/S0934-8840(98)80124-2] [PMID: 9563197]

[90] Jensen PM, Frandsen F. Temporal risk assessment for Lyme borreliosis in Denmark. Scand J Infect Dis 2000; 32(5): 539-44 [http://dx.doi.org/10.1080/003655400458848] [PMID: 11055661]

[91] Glass GE, Schwartz BS, Morgan JM III, Johnson DT, Noy PM, Israel E. Environmental risk factors for Lyme disease identified with geographic information systems. Am J Public Health 1995; 85(7): 944-8. [http://dx.doi.org/10.2105/AJPH.85.7.944] [PMID: 7604918]

Received: October 22, $2015 \quad$ Revised: December 16, 2015 Accepted: December 16, 2015

(C) Sala and De Faveri; Licensee Bentham Open.

This is an open access article licensed under the terms of the Creative Commons Attribution-Non-Commercial 4.0 International Public License (CC BY-NC 4.0) (https://creativecommons.org/licenses/by-nc/4.0/legalcode), which permits unrestricted, non-commercial use, distribution and reproduction in any medium, provided the work is properly cited. 